\title{
Increase in circulating levels of cardiac natriuretic peptides after hormone replacement therapy in postmenopausal women
}

\author{
Silvia MAFFEI, Silvia DEL RY, Concetta PRONTERA and Aldo CLERICO
}

* Laboratory of Cardiovascolar Endocrinology and Cell Biology, C.N.R. Institute of Clinical Physiology, Via Trieste, 4I 56126 Pisa, Italy

\section{A}

\begin{abstract}
The mechanisms that mediate the cardioprotective action of steroid hormones in postmenopausal women are poorly understood. To study the inter-relationship between female steroid hormones and cardiac natriuretic peptides, plasma levels of atrial natriuretic peptide (ANP) and brain natriuretic peptide (BNP) were measured in postmenopausal women, both before and after oestrogen replacement therapy. A total of 22 healthy postmenopausal women (mean age $51.9 \pm 4.6$ years) were enrolled in the study; all had been postmenopausal for at least I year and all reported climacteric symptoms accompanied by increased levels of folliclestimulating hormone $(>30 \mathrm{~m}$-i.u. $/ \mathrm{ml})$ and luteinizing hormone $(>20 \mathrm{~m}$-i.u. $/ \mathrm{ml})$, and a reduction in oestradiol $(<25 \mathrm{pg} / \mathrm{ml})$. All women were given hormone replacement therapy with transdermal oestradiol, either patch $(50 \mu \mathrm{g} / 24 \mathrm{~h})$ or gel ( $\mathrm{mg} /$ day), cyclically combined with oral dihydrogesterone ( $10 \mathrm{mg} /$ day for 12 days/month, on days $19-30$ of the month). ANP and BNP were measured directly in plasma samples with specific and sensitive immunoradiometric assays before and after hormone replacement therapy (transdermal oestradiol combined with oral dihydrogesterone). Body weight, arterial blood pressure and echocardiographic examination values did not change after hormone replacement therapy. As expected, serum oestradiol increased significantly and gonadotropins decreased as an effect of the hormone replacement therapy. On average, both ANP and BNP had increased significantly after 3 months of hormone replacement therapy [ANP: before treatment, $17.6 \pm 9.6 \mathrm{pg} / \mathrm{ml} ;$ after, $23.6 \pm 5.6 \mathrm{pg} / \mathrm{ml}(P=$ $0.0173)$; BNP: before treatment, $12.6 \pm 10.2 \mathrm{pg} / \mathrm{ml}$; after, $19.8 \pm 14.0 \mathrm{pg} / \mathrm{ml}(P<0.000 \mathrm{I})]$. Our study indicates that hormone replacement therapy for a period of 3 months induces a rise in the circulating levels of cardiac natriuretic hormones in postmenopausal women. Our data also suggest the working hypothesis that cardiac natriuretic peptides may play an important role in mediating the cardioprotective effects of female steroid sex hormones in women throughout life.
\end{abstract}

\section{INTRODUCTION}

The incidence of cardiovascular diseases is significantly lower in women of child-bearing age than in men, whereas after menopause this difference disappears [1,2]. Furthermore, a cardioprotective role of oestrogen re- placement therapy in postmenopausal women has been suggested in several studies [1,3-6].

An important pathophysiological mechanism in cardiovascular diseases is the imbalance between the vasoconstrictive/anti-natriuretic action of some neuroendocrine factors (including the renin-angiotensin-

Key words: ANP, BNP, hormone replacement therapy, IRMA, natriuretic peptides, oestrogens, progesterone.

Abbreviations: ANP, atrial natriuretic peptide; BNP, brain natriuretic peptide; FSH, follicle-stimulating hormone; IRMA, immunoradiometric assay; LH, luteinizing hormone.

Correspondence: Dr Aldo Clerico (e-mail clerico@iff.pi.cnr.it). 
aldosterone system, vasopressin and the sympathetic nervous system) and the counter-regulatory vasodilatory/ natriuretic effects of other factors, such as the cardiac natriuretic peptides $[7,8]$. The relationship between cardiac natriuretic hormones [i.e. atrial natriuretic peptide (ANP) and brain natriuretic peptide (BNP)] and female steroid sex hormones has been poorly investigated in humans $[1,9,10]$, although some studies suggest that female sex steroids may have some influence on the cardiac natriuretic hormone system.

Indeed, higher circulating levels of ANP and/or BNP have been observed in women than in men [11-13]. In addition, a 2-fold increase in plasma ANP levels has been found during the last trimester of pregnancy and in immediate puerperium $[14,15]$, while conflicting results concerning changes in plasma ANP or BNP levels during the menstrual cycle have been reported $[9,10,16-20]$. In some studies $[17,20]$, circulating levels of cardiac natriuretic peptides were found to be significantly higher during the follicular than the luteal phase of the menstrual cycle, whereas in other studies $[10,16,18,19]$ no differences were observed. Conflicting results were also obtained when ANP levels were measured in postmenopausal women before and after hormone replacement therapy: in one study [21] a significant decrease was found, while in another no significant variations were reported [22]. Finally, the plasma ANP level increased significantly in premenopausal women after administration of low-dose oral contraceptives [22].

In order to study the inter-relationship between female steroid sex hormones and cardiac natriuretic peptides in humans, we measured the plasma levels of ANP and BNP by means of highly sensitive and specific immunoradiometric assay (IRMA) methods $[11,13,23]$ in postmenopausal women, both before and after hormone replacement therapy. The data obtained from the group of postmenopausal women undergoing hormone replacement therapy have also been compared with a control group of postmenopausal women well matched for age and sodium intake.

\section{MATERIALS AND METHODS}

\section{Experimental subjects}

Informed consent was obtained from all women, who had received detailed information concerning the aims and nature of the study. The study was approved by the Ethics and Scientific Committee of the CNR Clinical Physiology Unit, Pisa, and was carried out in accordance with the Declaration of Helsinki (1989) of the World Medical Association.

\section{Treated group}

A total of 22 healthy postmenopausal women (nonsmokers; mean age $51.9 \pm 4.6$ years and range 48-61 years; body mass index $23.2 \pm 2.5 \mathrm{~kg} \cdot \mathrm{m}^{-2}$ ), who were about to start hormone replacement therapy for relief of postmenopausal symptoms, were enrolled in the study. Of these, 20 women had been postmenopausal for at least 1 year, and all reported climacteric symptoms accompanied by increases in the levels of follicle-stimulating hormine (FSH) $(>30 \mathrm{~m}$-i.u. $/ \mathrm{ml})$ and luteinizing hormone (LH) $(>20 \mathrm{~m}$-i.u. $/ \mathrm{ml})$ and a reduction in oestradiol $(<25 \mathrm{pg} / \mathrm{ml})$. The other two women were undergoing surgical menopause due to uterine fibroids (surgical operation performed at the age of 47 and 50 years respectively). During the study, all the women strictly followed a personalized diet, without caloric restriction (normocaloric), which was prescribed and checked at regular intervals by a dietician, as reported previously $[10,24,25]$. Furthermore, an M-mode, twodimensional Doppler echocardiographic examination was performed before and after 3 months of hormone repacement therapy.

Venous blood was drawn from each subject (fasting) for basal circulating oestradiol, LH, FSH, ANP and BNP evaluation. All the women were given hormone replacement therapy with transdermal oestradiol, patch $(50 \mu \mathrm{g} / 24 \mathrm{~h})$ or gel $(1 \mathrm{mg} /$ day), combined cyclically with oral dihydrogesterone $(10 \mathrm{mg} /$ day for 12 days/month on days 19-30 of the month). Due to the large variability in transdermal absorption, a blood venous sample was obtained to assess plasma levels of oestradiol, FSH and LH during the first 1 month of therapy. If oestradiol concentrations were below the physiological range for the follicular phase of the ovarian cycle, oestradiol gel therapy was administered instead of the patch preparation. After 3 months of treatment, blood was collected again for the evaluation of the circulating hormones and peptides described above. Plasma collection was performed on the second day of the fourth patch of the month and at the ninth hour after gel application during the oestrogenic phase of the hormone replacement therapy.

Since circulating levels of cardiac hormones (especially ANP) show large variation in normal subjects due to their short plasma half-lives, between five and seven blood samples were collected from each woman over a 15-min period, using a venous catheter $[9,10]$. To minimize the variation in hormone plasma concentrations, for each woman the mean of all ANP or BNP values measured in samples collected was then used for statistical analysis.

\section{Control group}

Plasma ANP and BNP levels were measured in a control group of postmenopausal women, including 21 healthy postmenopausal women well matched for age (mean age $53.1 \pm 4.6$ years; range $48-62$ years) and sodium intake with the group of postmenopausal women undergoing hormone replacement therapy. 
Table I Body weight, arterial blood pressure and hormone levels in 22 postmenopausal women (age $51.9 \pm 4.6$ years) before and after hormone replacement therapy

SBP, systolic blood pressure; DBP, diastolic blood pressure. Values are means \pm S.D. $P$ values were determined by paired $t$-tests; n.s., not significant.

\begin{tabular}{lccc}
\hline Parameter & Basal & After HRT & $P$ value \\
\hline Weight $(\mathrm{kg})$ & $61.0 \pm 7.0$ & $60.8 \pm 6.7$ & n.s. \\
SBP $(\mathrm{mmHg})$ & $124.6 \pm 15.2$ & $129.0 \pm 13.0$ & n.s. \\
DBP $(\mathrm{mmHg})$ & $72.3 \pm 10.6$ & $72.1 \pm 9.7$ & n.s. \\
Oestradiol $(\mathrm{pg} / \mathrm{ml})$ & $18.5 \pm 8.2$ & $63.6 \pm 43.0$ & $<0.0001$ \\
FSH $(\mathrm{m}-\mathrm{i} . \mathrm{u} . / \mathrm{ml})$ & $75.6 \pm 21.8$ & $38.6 \pm 13.4$ & $<0.0001$ \\
LH $(\mathrm{m}-\mathrm{i} . \mathrm{u} . \mathrm{ml})$ & $36.4 \pm 8.2$ & $24.1 \pm 8.3$ & $<0.0001$ \\
ANP $(\mathrm{pg} / \mathrm{ml})$ & $17.6 \pm 9.6$ & $23.6 \pm 5.6$ & 0.0173 \\
BNP $(\mathrm{pg} / \mathrm{ml})$ & $12.6 \pm 10.2$ & $19.8 \pm 14.0$ & $<0.0001$ \\
\hline
\end{tabular}

All subjects were non-obese and had arterial blood pressure in the normal range; they were free from acute diseases, and they denied any serious disease in the past, as well as the use of any drug during the 3 weeks prior to the study. In particular, the group of postmenopausal women denied any past use of sex steroid hormones for relief of postmenopausal symptoms. All of them had normal values for the main plasma parameters (including creatinine, urea nitrogen, glucose, uric acid, albumin, enzymes, electrolytes and haemoglobin), and normal erythrocyte and leucocyte counts and urine analysis.

\section{Assay methods}

\section{Plasma samples}

After collection, blood samples $(10 \mathrm{ml})$ were immediately put into ice-chilled disposable polypropylene tubes containing aprotinin (500 kallikrein-inhibitory units $/ \mathrm{ml}$ of plasma) and EDTA (1 $\mathrm{mg} / \mathrm{ml}$ of plasma). Plasma samples were separated rapidly by centrifugation at $2000 \mathrm{~g}$ for $5 \mathrm{~min}$ at $4{ }^{\circ} \mathrm{C}$, and then frozen and stored at $-20^{\circ} \mathrm{C}$ in $1 \mathrm{ml}$ aliquots in polypropylene tubes until assay.

\section{Hormone assays}

Plasma levels of ANP and BNP were measured with twosite (sandwich) IRMA methods, which do not require a preliminary step for extraction or purification of plasma samples (direct assay), as described previously in detail $[11,13,23]$. These methods were chosen for this study due to their high degree of sensitivity (approx. 2-3 pg/ml), precision (between-assay variability ranging from $5 \%$ to $12 \%$ ) and accuracy, since it is well known that the competitive immunoassay methods usually employed for the assay of cardiac natriuretic peptides are unable to measure ANP and BNP concentrations in the normal range with acceptable precision [9,26,27].

Serum oestradiol was measured by means of a competitive chemiluminescent immunoassay kit (Immulite Analyzer ${ }^{\circledR}$; DPC), and LH and FSH levels were measured using non-competitive chemiluminescent

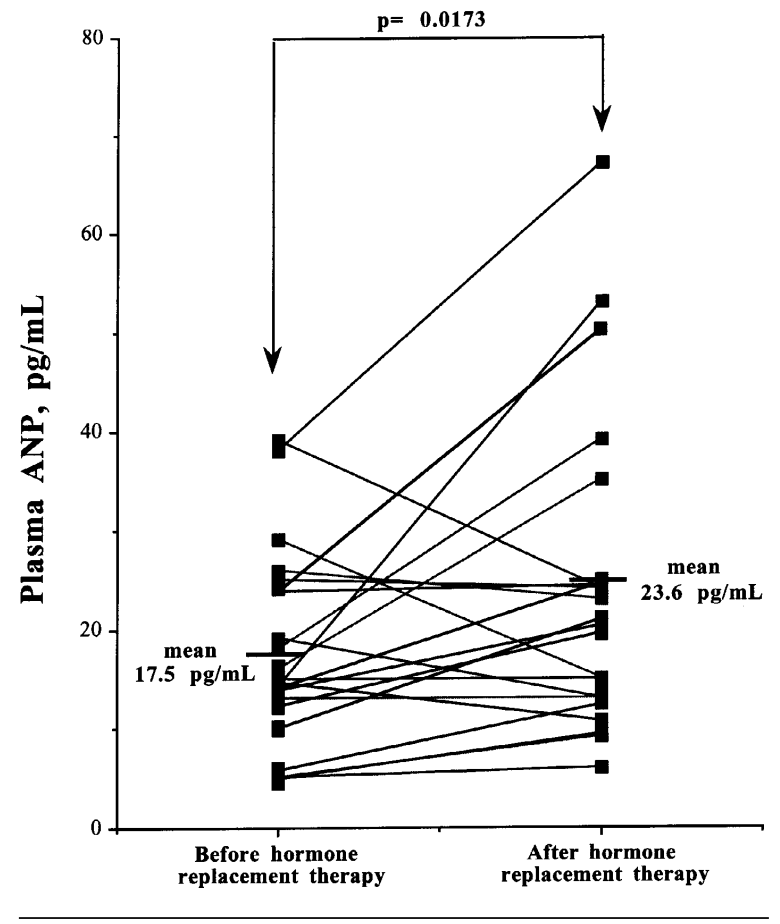

Figure I Individual values for plasma ANP levels measured in the 22 postmenopausal women before and after 3 months of hormone replacement therapy

The horizontal lines indicate mean values. The level of statistical significance with respect to the basal value was calculated by paired $t$ test after logarithmic transformation of the original values.

immunoassay kits (Access ${ }^{\circledR}$; Sanofi Pasteur). For all these methods the intra-assay coefficient of variation was $\leqslant 10 \%$, and the between-assay coefficient of variation was $\leqslant 15 \%$, for the range of serum hormone concentrations observed in the present study.

\section{Statistical analysis}

Statistical analysis was carried out using the Stat-View 5.0.1 program (1992-1998; SAS Institute Inc., Cary, NC, U.S.A.). Because ANP and BNP levels in healthy subjects are not normally distributed, the logarithmic transform- 


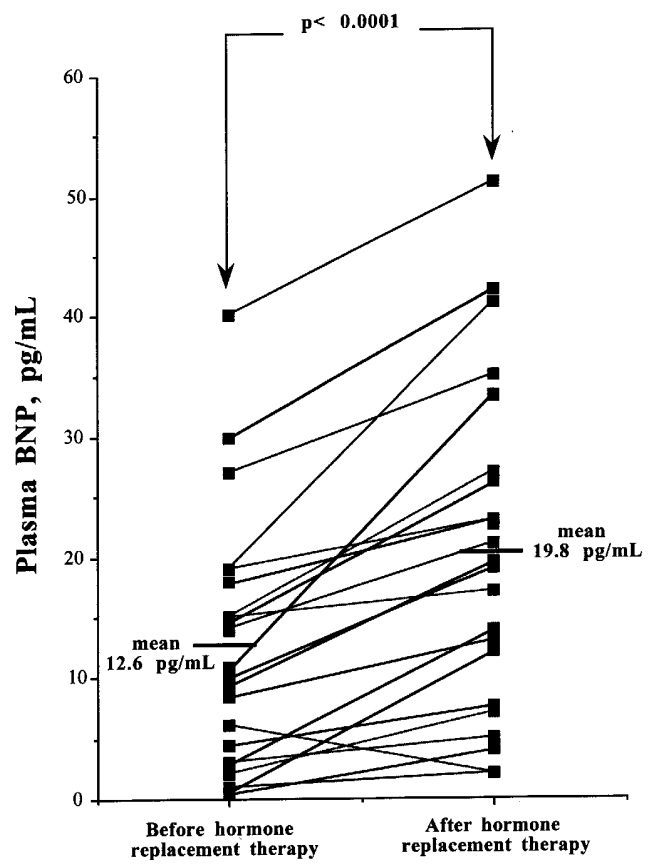

Figure 2 Individual values for plasma BNP levels measured in the 22 postmenopausal women before and after 3 months of hormone replacement therapy

The horizontal lines indicate mean values. The level of statistical significance with respect to the basal value was calculated by paired $t$ test after logarithmic transformation of the original values.

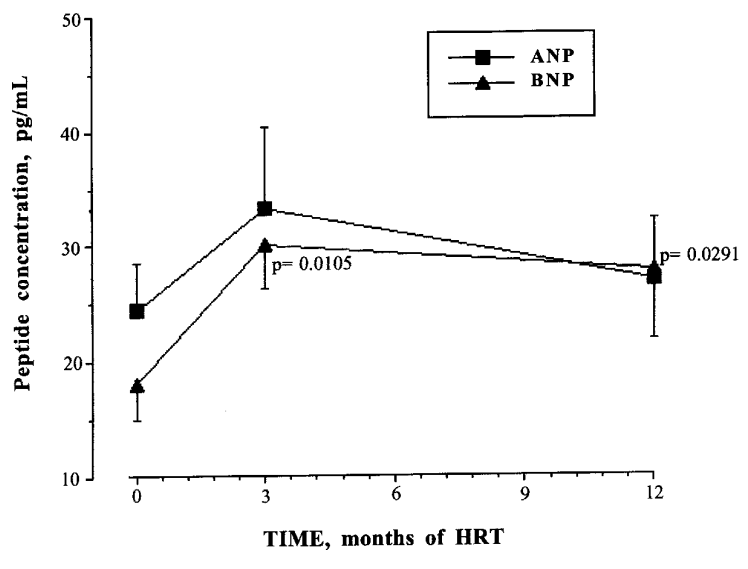

Figure 3 Plasma levels of ANP and BNP in seven postmenopausal women in the basal condition, and after 3 and 12 months of hormone replacement therapy (HRT)

The level of statistical significance with respect to the basal value for BNP concentrations was calculated after repeated-measures ANOVA by the Fisher's protected least significant difference test.

ation of data was used for statistical analysis when necessary. For comparisons between two paired groups, Student's paired $t$ test was used (i.e. data reported in Table 1 and Figures 1 and 2). Moreover, data from more than two independent groups were analysed by repeatedmeasures ANOVA (i.e. data reported in Figure 3). The results are expressed as means \pm S.D. if not otherwise stated.

\section{RESULTS}

Mean weight, arterial blood pressure and hormonal values in postmenopausal women before and after 3 months of hormone replacement therapy are reported in Table 1. As expected, serum oestradiol levels increased significantly and gonadotropin levels decreased as an effect of the hormone replacement therapy.

Body weight and blood pressure did not differ before and after hormone replacement therapy (Table 1). Furthermore, echocardiographic examination did not show any changes in wall thickness and/or chamber diameters after 3 months of hormone replacement therapy (e.g. left atrium: before, $35.0 \pm 3.4 \mathrm{~mm}$; after, $36.2 \pm 3.1 \mathrm{~mm}$; septum thickness: before, $9.00 \pm 0.82 \mathrm{~mm}$; after, $8.83 \pm$ $0.94 \mathrm{~mm}$; thickness of posterior wall: before, $9.00 \pm$ $1.00 \mathrm{~mm}$; after, $9.92 \pm 1.17 \mathrm{~mm}$; diastolic left ventricular diameter: before, $43.9 \pm 3.2 \mathrm{~mm}$; after, $44.6 \pm$ $2.5 \mathrm{~mm})$.

Figures 1 and 2 report individual ANP and BNP levels measured before and after 3 months of hormone replacement therapy in the 22 postmenopausal women. On average, levels of both ANP $(+34.1 \%)$ and BNP $(+57.1 \%)$ increased significantly after hormone replacement therapy. However, BNP levels increased in a significantly greater number of postmenopausal women $\left(\chi^{2}\right.$-square test: $\left.P=0.0089\right)$ after hormone replacement therapy (21 women out of $22 ; 95.5 \%$ ) compared with ANP values (14 women out $22 ; 63.6 \%$ ).

Furthermore, it was possible to collect plasma samples from seven women after a total of 12 months of hormone replacement therapy for the assay of cardiac natriuretic peptides (Figure 3). BNP levels were significantly increased with respect to the basal values throughout the entire study period, up to 12 months of treatment with hormone replacement therapy (repeated-measures ANOVA: $P=0.0236$ ).

Finally, the group of postmenopausal women undergoing hormone replacement therapy had mean circulating levels of cardiac natriuretic peptides that were higher (although only BNP values showed a significant difference) than those of a control group comprising 21 healthy postmenopausal women well matched for age and sodium intake [values for control group: BNP, $11.1 \pm 9.1 \mathrm{pg} / \mathrm{ml}(P=0.0389$ by unpaired $t$ test compared with hormone replacement therapy group); ANP, $19.8 \pm 11.7 \mathrm{pg} / \mathrm{ml}(P=0.3603)]$.

\section{DISCUSSION}

Our data indicate that hormone replacement therapy with transdermal oestrogens for 3 months, which 
achieves serum oestradiol concentrations in the physiological range along with a fall in serum gonadotropin levels, induces an increase in circulating levels of cardiac natriuretic peptides.

To our knowledge, only two studies have investigated the effects of hormone replacement therapy on circulating levels of ANP in postmenopausal women. One study [22] reported no significant increase in ANP levels in 17 postmenopausal women during hormone replacement treatment. Another study [21] found a significant decrease in 13 postmenopausal women after 3 months of hormone replacement therapy. At present, it is difficult to explain these conflicting results. However, these two studies [21,22] and ours used different experimental protocols (with regard to both sample collection and drugs administered) as well as assay methods (RIA compared with IRMA). To our knowledge, no previous study has examined the effects of hormone replacement therapy on circulating levels of BNP.

Previous studies from our laboratory have indicated that no significant changes over a period of several days (or months) are observed in plasma levels of cardiac natriuretic hormones, including those of normal cycling women studied in different phases of the menstrual cycle, when a study protocol requiring 5-7 blood samples collected at rest over a $15-\mathrm{min}$ period is used $[9,10]$. In the present study, we also found increased plasma levels of cardiac natriuretic peptides after 12 months of hormone replacement therapy in seven postmenopausal women. Furthermore, BNP levels in postmenopausal women undergoing hormone replacement therapy were found to be significantly increased with respect to those in a control (untreated) group of postmenopausal women. These data, taken as a whole, strongly suggest that the increase in plasma levels of cardiac natriuretic hormones after hormone replacement therapy is due to a specific pharmacological effect, and therefore should not be considered to be a spurious finding and/or an aleatory event, such as the regressionto-the-mean phenomenon. It is also important to note that an aleatory event would affect both ANP and BNP systems in a similar manner, while in our study BNP levels showed a greater increase than those of ANP; this suggests a specific pharmacological effect on this hormone system.

An increase in circulating levels of ANP and BNP may theoretically be due to either an increase in hormone production/secretion or a decrease in peptide degradation (i.e. via specific neutral peptidases and clearance receptors) [9,27-31].

Since collection of plasma for hormone assays was performed during the oestrogenic phase of the hormone replacement therapy, the stimulatory effects on the ANP/BNP hormone system, observed in the present study, may be due to an oestrogenic action. As reviewed previously [1], there are two possible ways in which cardiac natriuretic peptide production can be affected by oestrogens: one is by a direct effect on cardiac gene expression and/or release, and the other is by one or more mediator mechanisms. Some authors have suggested that the increase in cardiac natriuretic peptide levels during oestrogen treatment may be secondary to activation of the renin-angiotensin-aldosterone system, which in turn affects vascular compliance and plasma volume $[1,22]$. However, no significant increases in serum renin activity or aldosterone levels were found in postmenopausal women after hormone replacement therapy [22].

Since the best-known stimulatory mechanisms for the release and/or production of cardiac natriuretic peptides are the stretch and hypertrophic growth of myocardiocytes [28-30], a possible effect of hormone replacement therapy on the cardiac camera dimension, the thickness of the parietal wall and the interventricular septum was evaluated by means of Doppler echocardiographic examination. However, no significant changes in cardiac camera dimension, the thickness of the parietal wall or the interventricular septum were found after 3 months of hormone replacement therapy in the postmenopausal women we studied.

As yet, no comprehensive and systematic study is available on the effects of sex steroid hormones on ANP and BNP gene expression and release [1]; therefore it is still unclear whether gonadal hormones can directly affect the production and secretion of cardiac natriuretic peptides by the human heart. There are also no data available concerning a possible inhibitory effect of sex steroid hormones on the mechanisms responsible for degradation of the cardiac natriuretic hormones. However, such an effect would seem to be an unlikely explanation for data obtained in the present study, because a non-specific inhibition of degradative pathways would be expected to increase the plasma concentrations of both ANP and BNP, and most probably those of ANP to a greater extent than those of BNP, because the rate of turnover of ANP is greater than that of BNP [31].

The incidence of cardiovascular disease is significantly lower in women during their child-bearing years than in men, whereas after menopause this difference disappears $[1,2]$. Furthermore, cardiovascular mortality in postmenopausal women receiving hormone replacement

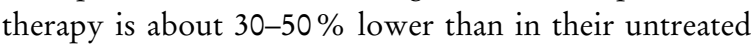
counterparts [1,2]. For these reasons, it was suggested that female sex steroid hormones may have a cardioprotective effect in women, even if their mechanism of action is unclear at present [1]. However, several studies indicate that the cardioprotective effect of hormone replacement therapy in menopausal women may be due, at least partly, to the effects of sex steroid hormones (especially oestrogens) on vascular tone and/or endothelial function $[1-6,32]$.

The cardiac natriuretic hormones have several im- 
portant physiological actions, offering some beneficial effects in cardiovascular disorders [1,8,9,28-31], including: (a) a decrease in blood pressure; (b) an increase in natriuresis and diuresis; (c) inhibition of the sympathetic nervous system and of the release or action of several hormones, including aldosterone, angiotensin II, endothelins, renin and vasopressin. It is important to underline that some of these endogenous substances are also produced in endothelial cells and/or other vascular tissues; consequently, cardiac natriuretic hormones should also have a protective effect on endothelium function by inhibiting the action of some of these neurohormones. Indeed, vascular tissues, as well as platelets [33], are rich in specific receptors for cardiac natriuretic peptides; in addition, the endothelium produces and secretes a peptide of the same family of cardiac natriuretic hormones, called C-type natriuretic peptide [34].

Therefore it can be hypothesized that the cardioprotective action of hormone replacement therapy in postmenopausal women may be mediated, at least in part, by increased circulating levels of cardiac natriuretic peptides. Indeed, some studies suggest that steroid sex hormones significantly affect the gene expression and production of cardiac natriuretic peptides, but no data are available to indicate whether this is the result of direct or indirect effects of female sex steroid hormones [1]. However, irrespective of the pharmacological mechanism of hormone replacement therapy, its effect seems to be more pronounced on levels of BNP compared with ANP, probably because ventricular myocardial tissue is affected more than are atrial cardiomyocytes. This is not surprising, because it is well known that ANP production/secretion in atrial myocardiocytes is regulated differently from BNP production/secretion in ventricular myocardial tissue [29].

In conclusion, our present study indicates that 3 months of transdermal oestrogen replacement therapy induces a rise in the circulating levels of cardiac natriuretic peptides in postmenopausal women. Our data also suggest the working hypothesis that cardiac natriuretic peptides may play an important role in mediating the cardioprotective effects of female steroid sex hormones in women throughout life.

\section{REFERENCES}

1 Kuroski de Bold, M. L. (1999) Estrogen, natriuretic peptides and the renin-angiotensin system. Cardiovasc. Res. 41, 524-531

2 Rosano, G. M. C., Chierchia, S. L., Leonardo, F., Beale, C. M. and Collins, P. (1996) Cardioprotective effects of ovarian hormones. Eur. Heart J. 17 (Suppl. D), 15-19

3 Sotelo, M. and Johnson, R. S. (1997) The effects of hormone replacement therapy on coronary heart disease. Endocrinol. Metab. Clin. North Am. 26, 313-328

4 Johnson, S. R. (1998) Menopause and hormone replacement therapy. Med. Clin. North Am. 82, 297-320
5 Clinical Synthesis Panel on HRT (1999) Hormone replacement therapy. Lancet 354, 152-155

6 Lakatta, E. G. and Boluyt, M. O. (2000) Age-associated changes in the cardiovascular system in the absence of cardiovascular disease. In Congestive Heart Failure, 2nd edn (Hosenpud, J. D. and Greenberg, B. H., eds.), pp. 137-156, Lippincott Williams \& Wilkins, Philadelphia

7 Katz, A. M. (2000) Heart Failure: Pathophysiology, Molecular Biology, and Clinical Management, Lippincott Williams \& Wilkins, Philadelphia

8 Cody, J. R. (2000) Hormonal alterations in heart failure. In Congestive Heart Failure, 2nd edn (Hosenpud, J. D. and Greenberg, B. H., eds), pp. 199-212, Lippincott Williams \& Wilkins, Philadelphia

9 Clerico, A. Iervasi, G. and Mariani, G. (1999) Clinical relevance of the measurement of cardiac natriuretic peptide hormones in humans. Horm. Metab. Res. 31, 487-498

10 Maffei, S., Clerico, A., Iervasi, G. et al. (1999) Circulating levels of cardiac natriuretic hormones measured in women during menstrual cycle. J. Endocrinol. Invest. 22, $1-5$

11 Clerico, A., Iervasi, G., Del Chicca, M. G. et al. (1998) Circulating levels of cardiac natriuretic peptides (ANP and BNP) measured by highly sensitive and specific immunoradiometric assays in normal subjects and in patients with different degrees of heart failure. J. Endocrinol. Invest. 21, 170-179

12 Jensen, K. T., Carstens, J., Ivarsen, P. and Pedersen, E. B. (1997) A new, fast, and reliable radioimmunoassay of brain natriuretic peptide in human plasma; reference values in healthy subjects and in patients with different diseases. Scand. J. Clin. Lab. Invest. 57, 529-540

13 Del Ry, S., Clerico, A., Giannessi, D. et al. (2000) Measurement of brain natriuretic peptide in plasma samples and cardiac tissue extracts by means of an IRMA method. Scand. J. Clin. Lab. Invest. 60, 81-90

14 Irons, D. W., Bayles, P. H. and Davison, J. M. (1996) Effect of atrial natriuretic peptide on renal hemodynamics and sodium excretion during human pregnancy. Am. J. Physiol. 271, F239-F242

15 Rutherford, A. J., Anderson, J. V., Elder, M. G. and Bloom, S. R. (1987) Release of atrial natriuretic peptide during pregnancy and immediate puerperium. Lancet $\mathbf{i}$, 928-929

16 Tan, A. C. I. T. L., Rosmalen, F. M. A., Theelen, B. G. A., Kloppenborg, P. W. C., Benraad, H. B. and Benraad, T. J. (1987) Atrial natriuretic peptide - the influence of various physiological and sampling conditions. Ann. Clin. Biochem. 24, 500-507

17 Jensen, L. K., Svanegaard, J. and Husby, H. (1989) Atrial natriuretic peptide during menstrual cycle. Am. J. Obstet. Gynecol. 161, 951-952

18 Clark, B. A., Elahi, D. and Epstein, F. H. (1990) The influence of gender, age, and the menstrual cycle on plasma atrial natriuretic peptide. J. Clin. Endocrinol. Metab. 70, 349-352

19 Yeko, T. R., Rao, P. S., Parsons, A. K., Mayer, J. C., Graham, L. B. and Maroulis, G. B. (1995) Atrial natriuretic peptide, oestradiol and progesterone in women undergoing spontaneous and gonadotropin-stimulated ovulatory cycles. Hum. Reprod. 10, 2872-2874

20 Trigoso, W. F., Wesly, J. M., Meranda, D. L. and Shenker, Y. (1996) Vasopressin and atrial natriuretic hormone response to hypertonic saline during the follicular and luteal phases of the menstrual cycle. Hum. Reprod. 11, 2392-2395

21 Spinetti, A. Margutti, A., Bertolini, S. et al. (1997) Hormonal replacement therapy affects calcitonin generelated peptide and atrial natriuretic peptide secretion in postmenopausal women. Eur. J. Endocrinol. 137, 664-669

22 Davidson, B. J., Rea, C. D. and Valenzuela, G. (1988) Atrial natriuretic peptide, plasma renin activity, and aldosterone in women on estrogen therapy and with premenstrual syndrome. Fertil. Steril. 50, 743-746 
23 Clerico, A., Iervasi, G., Del Chicca, M. G. et al. (1996) Analytical performance and clinical usefulness of a commercially available IRMA kit for the measurement of atrial natriuretic peptide in patients with heart failure. Clin. Chem. 42, 1627-1633

24 Iervasi, G., Clerico, A. Berti, S. et al. (1993) ANP kinetics in normal men: in vivo measurement by a tracer method and correlation with sodium intake. Am. J. Physiol. 264, F480-F489

25 Iervasi, G., Clerico, A., Berti, S. et al. (1995) Altered tissue degradation and distribution of atrial natriuretic peptide in patients with idiopathic dilated cardiomyopathy and its relationship with clinical severity of the disease and sodium handling. Circulation 91, 2018-2027

26 Clerico, A., Iervasi, G., Del Ry, S. and Giannessi, D. (1999) Immunoassay methods for the measurement of natriuretic cardiac hormones (ANP, BNP, and related peptides) in humans. J. Clin. Ligand Assay 22, 194-204

27 Clerico, A., Del Ry, S. and Giannessi, D. (2000)

Measurement of natriuretic cardiac hormones (ANP, $\mathrm{BNP}$, and related peptides) in clinical practice: the need for a new generation of immunoassay methods. Clin. Chem. 46, 1529-1534
28 Clerico, A. and Iervasi, G. (1995) Alterations in metabolic clearance of atrial natriuretic peptides in heart failure: how do they relate to the resistance to atrial natriuretic peptides? J. Cardiac Failure 1, 323-328

29 De Bold, A. J., Bruneau, B. G. and Kuroski de Bold, M. L. (1996) Mechanical and neuroendocrine regulation of the endocrine heart. Cardiovasc. Res. 31, 7-18

30 Sagnella, G. A. (1998) Measurement and significance of circulating natriuretic peptides in cardiovascular diseases. Clin. Sci. 95, 519-529

31 Clerico, A., Iervasi, G. and Pilo, A. (2000) Turnover studies on cardiac natriuretic peptides: Methodological, pathophysiological and therapeutical considerations. Curr. Drug Metab. 1, 85-105

32 Teede, H. and McGrath, B. (1999) Cardiovascular effect of sex hormones. Clin. Sci. 97, 1-3

33 Giannessi, D., Andreassi, M. G., Del Ry, S., Clerico, A., Colombo, M. G. and Dini, N. (2001) Possibility of age regulation of the natriuretic peptide C-receptor in human platelets. J. Endocrinol. Invest. 24, 8-16

34 Chen, H. H. and Burnett, Jr., J. C. (1998) C-type natriuretic peptide: the endothelial component of the natriuretic peptide system. Cardiovasc. Pharmacol. 32 (Suppl. 3), S22-S28

Received 31 January 200I/27 April 200I; accepted 29 June 200 I 